* Una primera versión de este texto fue presentada en el coloquio "Homenaje a Carlos Rincón. Rutas de la crítica cultural y literaria en Colombia y Latinoamérica", en octubre 31 de 2019. Esta versión ajustada de esa ponencia conserva los rasgos de la presentación oral. Agradezco los comentarios de Sven Schuster.

Cómo citar este artículo: Sánchez Lopera, A. (2021). Colombia inmanente. Escribir la historia desde la estética política (y no desde la mentira). Estudios de Literatura Colombiana 48, pp. 41-57. DOI: https://doi. org/10.17533/udea.elc.n48a02

1 https://orcid.org/0000-0003-1602-2071 als219@pitt.edu

University of Pittsburgh, United States

Editores: Andrés Vergara Aguirre, Christian Benavides Martínez, Valentina Noreña Gómez

Recibido: 15.02 .2020

Aprobado: 28.10 .2020

Publicado: 18.12 .2020

Copyright: (92021 Estudios de Literatura Colombiana. Este es un artículo de acceso abierto distribuido bajo los términos de la Licencia Creative Commons AtribuciónNo comercial - Compartir igual 4.0 Internacional

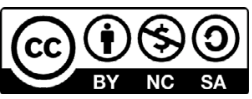

\section{Colombia INMANENTE. Escribir LA HISTORIA DESDE LA ESTÉTICA POLÍTICA (Y NO DESDE LA MENTIRA)*}

\author{
Immanent Colombia. Writing history \\ FROM POLITICAL AESTHETICS (AND NOT \\ FROM LIES)
}

Alejandro Sánchez Lopera ${ }^{1}$

Resumen: este texto fue escrito en respuesta a la muerte del destacado crítico literario colombiano Carlos Rincón (19372018). Analiza sus dos últimos libros de autor publicados en Colombia, Íconos y mitos culturales en la invención de la nación en Colombia (2014) y Avatares de la memoria cultural en Colombia. Formas simbólicas del Estado, museos y canon literario (2015). El análisis se hace no sobre el contenido específico de ambos libros, sino sobre su maqueta, su plano. No se revisa qué dijo Rincón allí; se estudia cómo dijo lo que dijo. Se plantea que ese cómo permite entrever fragmentos de la historia de una Colombia global desde el ángulo de la estética política.

Palabras clave: Carlos Rincón; estética; historia de Colombia; verdad; mentira.

Abstract: This text was written in response to the death of the prominent Colombian literary critic Carlos Rincón (19372018). It analyzes his last two authored-books published in Colombia, Íconos y mitos culturales en la invención de la nación en Colombia (2014) and Avatares de la memoria cultural en Colombia. Formas simbólicas del Estado, museos y canon literario (2015).The analysis is done not on the specific content of both books, but on their sketch, their plan: the text does not review what Rincón said. Instead, it studies how he said what he said. It is suggested that this how allows us to glimpse fragments of the history of a global Colombia from the angle of political aesthetics.

Keywords: Carlos Rincón; aesthetics; Colombian history; truth; lies. 
"Eres también aquello que has perdido"

Jorge Luis Borges

Los conjurados

La partida de Carlos Rincón en diciembre de 2018 dejó un sinnúmero de preguntas abiertas sobre el ejercicio de la crítica, la relación de la literatura con la teoría y el inestable lugar de América Latina en el mundo. Pues, ¿qué hacía un latinoamericano traduciendo tempranamente a Benjamin, Bajtin y a Adorno, desplazando el punto de vista desde las influencias hacia la estética de la recepción, al tiempo que dialogaba con Sergio Ramírez sobre la desestabilización norteamericana en Nicaragua?

Interrogantes como estos hablan de la potencia de su trabajo, así como de algunas de sus desventuras y el lugar tantas veces marginal que ha ocupado su obra escrita, que combinó con la enseñanza desde 1970 en Alemania, primero en el Romanisches Institut de la Karl-Marx-Universität de Leipzig, y luego en la Freie Universität de Berlín, donde fue profesor emérito. Hay un interrogante en particular que, a mi modo de ver, expresa la confusión, molestia y ansiedad frente al trabajo de Rincón: ¿cómo alguien nacido en la periferia osaba pasar en sus textos de un continente a otro, de un autor e idioma a otros, sin pena ni permiso solicitado? En sus momentos más lúcidos y creativos, así como en los de más vacilación y debilidad, Rincón viene entonces a nuestro encuentro con más dilemas de los que tal vez esperábamos.

Para recorrer parte de esos momentos, me centraré en sus dos últimos libros de autor publicados en Colombia, donde entre luminosidades y penumbras nos ofrece un retrato particular - de corte estético, es mi lectura - de esa maraña de hábitos entretejidos entre la cultura, la economía y la política de un país en medio de la globalización. El primero de ellos, Íconos y mitos culturales en la invención de la nación en Colombia (2014), abarca artículos sobre pluriculturalidad, símbolos coloniales, bicentenarios y mitomanías como la de la Atenas Suramericana; y el segundo, Avatares de la memoria cultural en Colombia. Formas simbólicas del Estado, museos y canon literario (2015), contiene textos variados sobre símbolos, escudos y mapas, canon literario y políticas museográficas. El arco temporal que cubren ambos libros es igualmente variado, o mejor, segmentado, pues Rincón elige cortes en diferentes momentos: desde la Colonia, con un estudio del retrato del conde de Cartagena, el general Pablo Morillo, hasta el momento actual, con un retrato fotográfico de 2012 del entonces presidente Juan Manuel Santos, nieto segundo del expresidente Eduardo Santos (1934-1938), quien aparece 
rodeado, en una perversa repetición, de varios de los demás ministros y expresidentes de su generación. Si proyectáramos sobre esa fotografía una suerte de maqueta subyacente imaginaria, siguiendo el análisis de Rincón de la génesis de la superficie pintada del retrato de Morillo — composición, agregados, bocetos—, encontraríamos en esa foto-retrato una instantánea de una genealogía anti-nietzscheana, entendida como linaje y no como procedencia, como tronco - la mismidad, el "eso mismo" carcomiéndose, re-trayéndose, en una suerte de repetición sin diferencia- (2014c).

Es cierto que criticar las complicidades de grandes sectores de las academias colombianas, letrados e intelectuales “públicos” ya no es algo novedoso. Menos en las últimas décadas con la oleada de críticas a la "ciudad letrada”. Pero Rincón no solo se adelantó décadas a esas críticas —incluso a la de Ángel Rama, quien, de hecho, recogió las botellas que Rincón arrojó al mar con sus traducciones de Bajtín y Benjamin-; siempre fue más allá, franqueando la línea. Instauró, en un movimiento similar al de Rafael Gutiérrez Girardot, una polémica no tanto contra alguien, sino contra algo sumamente reverencial en nuestro país: efectuó, en tono irónico y oblicuo, un ataque a la majestad de las instituciones y de los valores.

Luego de desmontar la glorificación de Rafael Pombo y Jorge Isaacs, de evidenciar, en palabras de Gabriel García Márquez, a la literatura colombiana como "un fraude a la nación”, Rincón procede a mostrar lo que significó el exceso de gramáticos - y la práctica ausencia de filólogos - en Colombia.

Entre todos los conocimientos elementales que podían faltarles [a Caro, Cuervo, Suárez y Marroquín] uno habría de resultar destructivo. La visión que podían tener de la historia y la filología hizo que les fuera ajena, entre otras básicas, la idea de que a través de los tiempos la edición de textos hispanos, considerados por ellos "anteclásicos" o "clásicos", habían respondido siempre a necesidades y exigencias políticas, sociales y culturales diferentes. No pudieron darse cuenta de que la fijación de un texto resultaba inseparable de una actividad hermenéutica o que la autoridad de los textos y con ella su "fortuna póstuma" se fundamentaba en la práctica de la lectura (Rincón, 2014a, p. 23I).

Es decir, ausencia total de las mediaciones mínimas, obnubilados como estaban esos gramáticos por la refundación y el reinicio de Grecia en los Andes. Es precisamente a esas mediaciones a las que apuntan los trabajos de Rincón, a la operación de los modos de socialización, particularmente a la luz de ciertas medialidades: objetos, instituciones, símbolos. Socialidades y medialidades que son fáciles de nombrar mas no de discernir; de enunciar mas no escudriñar en su operación efectiva. 
Pienso por ejemplo en el "consenso" que hubo, y hay, en diversos sectores, sobre la “postergación de la modernidad" en Colombia. La enorme diferencia de Rincón con respecto a esos diagnósticos es que su obra muestra no qué es, sino cómo funciona esa esquiva y multifacética relación colombiana y latinoamericana con "lo moderno". Frente a la significativa literatura en torno a nuestra no modernidad o nuestra antimodernidad, los textos de Rincón inquieren no si hay o no dominación de estratos reactivos o refractarios al acontecimiento, o bloqueos a "lo moderno" (y "lo posmoderno"). Más bien, cómo operan las dominaciones y los sedimentos que conducen a ello. Específicamente, cómo operan los prejuicios tanto en los discursos como en las prácticas. Sus dos últimos libros tratan de entender, en su practicidad, cómo hemos llegado a ser lo que somos — para poder quizás dejar de serlo, o ser otra cosa, cambiando el verbo ser por el de devenir-. Lo que queda por saber es, si a diferencia de quienes han lamentado esa postergación de la modernidad colombiana, Rincón logra inmiscuirse en la suerte de "empresa radical del desengaño" que toma distancia de la decepción frente a eso que hemos sido.

Es por eso que frente a la acidez de su crítica a "lo propio", algunos críticos entonces ven en el esfuerzo de Rincón una suerte de universalismo velado, de "patrón Occidental de evolución universalizado”, como es el caso del historiador Renán Silva (Silva, 2017, p. 140). En eso tiene parte de razón el crítico, pues Rincón, no obstante conocer bastante el desacople de los tiempos y las no simultaneidades, a veces sucumbe a la tentación de la falta — aludiendo a que a nadie, a ninguna institución se le ocurrió esto o aquello-. El asunto, sin embargo, es aún más complejo, pues Colombia ni siquiera estaba en sintonía con los sucesos y procesos de las otras naciones latinoamericanas y caribeñas — por no hablar, del resto del mundo—. En la apostilla a su análisis del retrato de Morillo titulada Sin el pathos, Rincón avanza una comprobación, "sin el pathos de una gran conclusión anticipada":

Bolívar y su ejército inscribieron el nuevo país dentro de un gran ciclo histórico, pero no en la época de las revoluciones. Ese país no hizo suya la lección de Saint-Domingue, tampoco los cambios que dieron lugar al mundo moderno, ni conoció anarquismo o nacionalismo democrático (Rincón, 2014b, p. 135).

Más que ante un patrón evolutivo universal, estamos frente a un análisis efectivamente global, un plano donde lo local, por más autóctono, propio o pintoresco que se quiera, es un haz de relaciones en permanente flujo y contaminación con el mundo. Por más consignas identitarias y territoriales que profiera el ideólogo o el gramático, 
opera una especie de jalonazo, si se quiere ontológico, de transversalidad, ya que "no existen términos simples anteriores a las relaciones, porque esos términos ya son, por sí mismos, relaciones" (Scavino, 1999, s.p.). En ese sentido, leer lo que efectivamente se produjo, sin el correlato de lo que sucedía simultáneamente en otras partes, puede llevar a enfocar autores que escribían como si Marx, Nietzsche o Freud no hubieran existido. Podemos mirar lo que existe. Pero si lo existente es mediocre, mezquino, o conduce a la impotencia, entonces hay que mirar hacia otro lado, hacia muchos lados a la vez, multiplicando los puntos de vista. Es decir, si lo que tenemos es Miguel Antonio Caro y Rafael Núñez, estamos en serios aprietos si se quiere construir un punto de vista "crítico", o novedoso. Tomemos el debatido caso de la filosofía. El problema no es tanto si hay o no filosofía, pensamiento, en o de América Latina o Colombia: el punto es el modo de relación con el concepto. Ernesto Hernández (2019) lo plantea bellamente de esta manera, para el territorio latinoamericano:

[...] en América Latina se trata de una no-filosofía, en el sentido en que es el movimiento de un pensamiento por inscribirse en un plano filosófico que busca, ese movimiento, captar el concepto que, sin embargo, le es ajeno... es simplemente una intuición susceptible de error. En esa misma medida, se dan algo así como dos modos, dos modalidades para captar el concepto, una que busca captar el concepto por imitación (Dussel, o los epígonos de Ortega y Gasset...); y otra -infinitamente más potente - que busca captar-usar el concepto pero por medios desemejantes, tal la literatura, tanto el poema como la novela, el cuento (Borges y Vallejo) (s.p.).

En ese sentido, allí donde algunos lectores ven simple pedantería o erudición en Rincón, parecen más bien asomarse líneas para iniciar preguntas de investigación: insinuaciones que dejó un fabulador para seguir poblando mapas cuyo trazado sigue siendo incierto. Su obra parece más bien un plegable, un complejo plegado: un origami. Un conjunto de pliegues que, quizás, otros más desplegarán después. Esos pliegues que componen el trabajo de Rincón son, por supuesto, desiguales entre sí. Y no dan tregua alguna al lector. Por eso leer en heterogeneidad es lo que permite no simplemente ver retazos en los textos de Rincón. Permite captar que en cada pliegue están todos los demás: en cada punto está el universo entero, "el agua está llena de peces, los peces de agua”. Es el ejemplo que Deleuze (2006) encuentra en Leibniz: cada pliegue, una meseta; y al final, mil mesetas más: "Escuchan el mar y oyen el ruido de una ola... Oigo el ruido de una ola, distingo una ola... Y Leibniz dice que no oirían la ola si no tuvieran una pequeña percepción inconsciente de cada una de las gotas” que forman la ola (p. 37). Entonces el pez son las líneas del mar que son él, 
la gota es la lluvia; la gota es el mar y toda el agua, toda el agua del mar. De "El Mar en la Plaza”, como bien lo vio Rincón en su insuperable uso de la serie de pinturas de Gustavo Zalamea, El mar en la plaza, naufragio, para estallar la mitomanía de la "Bogotá griega”. El mar que es Achab y Atenas naufragando en Sudamérica, que rebasa las cordilleras para inundar la plaza. La ballena blanca norteamericana que naufraga junto al Titanic travestido en Capitolio en los Andes, juntando el lado latino y el lado norte de América en único mar. "El mar en la plaza" es el del "presagio", dice Zalamea. La plaza de Bolívar es la plaza del naufragio, escribe Rincón. ${ }^{2}$

Por supuesto, Rincón no está solo en este esfuerzo crítico. Hay dos vetas de trabajo que considero muy valiosas, y con las cuales se puede contrastar su trabajo. La primera, todo un conjunto de historias que se están escribiendo "desde abajo", que muestran lo porosas que son las estrategias de sujeción. ${ }^{3} \mathrm{Y}$ muestran las resistencias, las pequeñas desobediencias. La segunda, es el estudio del corpus efectivo (no el corpus deseado o anhelado) de lo que se escribió en Colombia - lo cual es un camino no exento de paradojas, como mencioné- ${ }^{4}$ A mi modo de ver, Rincón es quien ha llevado más lejos la segunda y quien, además, provee la descripción más minuciosa posible de las dominaciones estético-políticas — para poder entonces saber a qué se resisten las desobediencias-. Lo llamativo de Rincón es que, no sin vacilaciones, cruza géneros de escritura y tabiques disciplinares sin caer en la rentable proclama de la transdisciplinariedad —-más adelante volveré sobre esto-. De ahí su particular estilo de pensar y escribir, y la pregunta que dejó como problema en vías de construcción: la cuestión estética en Colombia.

En uno de sus últimos textos, el postfacio al libro derivado del proyecto de investigación Fealdad, gracia y libertinaje. Estética y modernidad en el pensamiento colombiano [1940-1960], Rincón plantea cómo la debilidad en la reflexión sobre la cuestión estética, la incapacidad de sedimentarla en términos institucionales — no existen, según él, estudios sistemáticos sobre la cuestión estética en Colombia-, va a abrir un flanco

2

Véase la entrevista a Gustavo Zalamea sobre su serie de óleos en http://untelevision.unal.edu.co/detalle/ article/gustavo-zalamea.html

3 Pueden verse, entre otros, el volúmen compilado en 2015 por Max Hering Torres sobre microhistorias de la transgresión.

$4 \quad$ En este grupo encontramos, por ejemplo, los proyectos de Germán Marquínez Argote, y el de Manuel Rodríguez Miranda con la Biblioteca Virtual del Pensamiento Filosófico en Colombia, así como los recientes trabajos de Carlos Arturo López, Damián Pachón y Juan Guillermo Gómez, entre otros. 
inesperado para quien estaba esperando la constitución de esferas civiles autónomas, o la rutinización de las prácticas de conservación de los símbolos e imágenes colectivas.

De acuerdo con su análisis, en el marco de la modernización de la vida cotidiana finalizando la Segunda Guerra Mundial se habían dado en Colombia reflexiones sobre la belleza y la fealdad en los trabajos de Hernando Téllez y Eduardo Caballero. No obstante, en medio de dicha modernización, la estética se había hecho presente a través del consumo de mercancías y símbolos de algo que a muchos siempre ha parecido banal: "En Colombia la estética no ingresaba en ella [la vida cotidiana] con las artes populares, como en ese manifiesto práctico que representó Frida Kahlo y su Casa Azul en Coyoacán, sino muy sectorialmente, a través de la moda” (Rincón, 2018b, pp. 357-358). Todo esto conduciría a una historia sensorial, para la cual Rincón ha dado ya algunas puntadas, y suturas, para seguir captando las fabulaciones, y simulaciones, que pululan en nuestro cuerpo social.

Especialmente una de ellas: la incapacidad de producir mentiras en el arte y desde el arte y no en el sentido psicológico o moral, esto es, el no ser capaces de crear ilusiones para soportar, con frialdad, el carácter cruel y horrendo de la vida. En lugar de asumir, en sobriedad, ese carácter escindido e irremediable de la vida, se asume la voluntad de vivir sin adversarios y eliminarlos, uno a uno. Esto sitúa los dos libros de Rincón más allá de una disposición o experiencia frente al objeto artístico, pues no se trata solo de una historia de los diferentes hábitos de los estratos sociales. Es un trazado del juego de distancias, de separaciones - gobernantes y gobernados, placer y dolor, gozo y sufrimiento - Es decir, no es pues una historia de lo que se ve - las formas - Es una historia de lo no visible - las fuerzas - , de lo distinto y lo disímil, tal como escribe Jean-Luc Nancy (2002) en La imagen-lo distinto:

Lo distinto se mantiene apartado del mundo de las cosas en tanto que mundo de la disponibilidad. En ese mundo, las cosas están disponibles a un tiempo para el uso y de acuerdo con su manifestación. Lo que se retira de ese mundo no es de ningún uso, o bien de un uso por completo diferente, y no se presenta en la manifestación (una fuerza no es precisamente una forma: se trata además de entender en qué sentido la imagen no es una forma y no es formal) (p.Ir).

Pero, ¿pensar la estética en un país tan violento?, dicen algunos; frente a las urgencias, ¿hay acaso tiempo para ello?, inquieren otros. Dada la magnitud de las violencias y desigualdades que han existido en Colombia, el trabajo de Rincón a veces es visto como un ejercicio barroco, excesivo; interesante, pero quizás innecesario. Además de 
incomprensible, dicen varios más - a lo cual, de paso, Nietzsche diría que "hay algo ofensivo en ser comprendido", pues "comprenderlo todo es perdonarlo todo" -.${ }^{5}$ No obstante, en lugar de deslizarnos hacia la "estetización de la política" que diagnosticó Walter Benjamin (2003) en su momento, en cómo en el humano que se autocontempla "su autoenajenación ha alcanzado un grado tal, que le permite vivir su propia aniquilación como un goce estético de primer orden” (pp. 98-99), estos dos libros de Rincón ejecutan, precisamente, una estética de lo desigual, esto es, de las jerarquías.

Podemos establecer otro contraste de su trabajo con un libro reciente sobre historia de la Colombia de mediados del siglo xx. Me refiero al aclamado libro del historiador Robert Karl, La paz olvidada. Politicos, letrados, campesinos y el surgimiento de las FARC en la formación de la Colombia contemporánea, publicado en 2018 y presentado por el reconocido politólogo y economista norteamericano James Robinson como "una reinvención profunda de la historia colombiana, que hemos estado en mora de hacer”. En efecto, es un libro que puede ser leído sin el bagaje y exigencia presentes en los textos de corte histórico-estético de Rincón.

No obstante, al no asentarse en un punto de vista distante de la convención universitaria, o proveer al menos una malla conceptual sobre lo que entiende por violencia, por ejemplo, termina haciendo una hagiografía de las élites colombianas, un elogio del liberalismo colombiano - por eso el libro hace parte del consenso sobre lo "benéfico", pacífico y civilizador que para muchos fue el Frente Nacional [1958-1974]—. ${ }^{6}$ De hecho, el "éxito" de su prosa puede explicarse también por su cercanía al estilo neoconservador ya practicado por historiadores como Malcolm Deas y Eduardo Posada Carbó. ${ }^{7}$ Un libro que, al final, es incapaz de verdad. De decir verdad. Los dos últimos libros de Rincón sobre historia, política y cultura en Colombia pueden, en principio, llegar a menos lectores. Pero dicen verdad. Son capaces de ir y volver, en el juego de distancias, cercanías y separaciones, de la esthesis, la sensación, a la stasis: al retrato tanto de la guerra civil entre tipos sociales, como

5 Puede verse el texto de Rodrigo Zuleta (1997) sobre Rincón.

6 Pienso aquí en la saga de politólogos historiadores como Fernán González, Eduardo Pizarro e incluso Marco Palacios y Francisco Gutiérrez Sanín. En tiempo reciente, quizás el libro más sintomático de este enfoque "benéfico" es el compilado por Mónica Pachón, Eduardo Posada Carbó y Carlos Caballero: Cincuenta años de regreso a la democracia. Nuevas miradas a la relevancia histórica del Frente Nacional (2012).

7 Debo la alusión al éxito del libro de Karl, en relación con la escritura neoconservadora de Deas y Posada, a Sven Schuster. 
del sobrante, de la fracción y facción que no caben ni cuentan, la imagen del disenso y la discordia: la diferencia. " "Ahí están, esos son”, escribe Rincón en su radiografía de las élites a partir de la foto ya aludida, tomada durante la alocución presidencial al dar a conocer el fallo del Tribunal de La Haya sobre el diferendo con Nicaragua en 2012 (Rincón, 2014c, p. 338). “Ahí están, esos son”, dice, recortando la consigna de otras épocas — que finalizaba en "los que venden la nación”-, suturándola —ya ni siquiera aparece la nación para ser vendida-, en este penoso retrato de quienes además conforman parte de la respuesta al reciente mural sobre las miles de ejecuciones extrajudiciales perpetradas por el Ejército, borrado por las Fuerzas Armadas en Bogotá: “¿Quién dio la orden?”. ${ }^{9}$ Ahora, ¿qué significa escribir un libro legible? ¿Legible para quién? O, mejor, si se está escribiendo parte de la historia de las verdades y las dominaciones, ¿por qué habría que ser complaciente con el lector? Dice Mariano Rodríguez (2019), a propósito de aristocracias y elitismo, de Nietzsche:

Para descubrir ciertas verdades, para tratar con ellas, hace falta valor, mucho valor, y por supuesto no todo el mundo es valiente (co vais a decir que sí, que todos somos iguales en este punto?). Para descubrir ciertas verdades, en el caso de Nietzsche, hace falta tener una dilatada experiencia de la enfermedad y del dolor, y no todo el mundo la tiene, indiscutiblemente (p. 167).

Es decir, una cosa es la igualdad entre los humanos, otra el riesgo que implica el entrar en un proceso de verdad. En términos del cuidadoso análisis de Foucault, otro nietzscheano, isegoría — igualdad de palabra, igualdad en el derecho a la palabra-e isonomía —igualdad ante la ley— no son lo mismo que parresia — decir verdad-. ${ }^{10}$ Si este decir verdad se desplaza hacia las instituciones de conocimiento, resulta claro que el estilo de pensamiento y de escritura de Rincón es un abierto desafío al retorno de los hábitos de la ciencia empírico-analítica a las humanidades y las ciencias sociales: la indexación, la medición, la era de los "productos". De nuevo, ¿legible para quién? Los textos de Rincón polemizan contra la tendencia a reducir el conocimiento al "resultado de un proyecto de investigación”. En esa tendencia se pulverizan al tiempo la heteronomía de estilos y lo que se entiende por lo "empírico". Precisamente los dos últimos libros de Rincón muestran que un archivo sólido es tan "empírico" como

\footnotetext{
8 Sobre la noción de stasis puede verse la impresionante investigación de Nicole Loraux "Reflections of the Greek City on Unity and Division" (1991).

9 https://www.justiciaypazcolombia.com/campana-por-la-verdad-mural-quien-dio-la-orden/

$10 \quad$ Véase la distinción que hace Foucault (2009) en El gobierno de sí y de los otros (pp. 162-163).
} 
lo que la llamada metodología cuantitativa denomina el "dato". Sobre todo, muestra que problemas bien construidos atraviesan de manera fundamental aquello que, precisamente, consideramos como "empírico".

No sorprende entonces que un historiador tan anti-posmoderno como Renán Silva, en su reseña ya mencionada del libro Avatares de la memoria, tome prestada la expresión que Lucien Febvre utilizó para analizar el trabajo del polémico Julien Benda - un "volumen con formato de novela"-: "Historia de tesis". Esto es, un clamor, hecho a partir de deducciones, un llamado a-sistemático... en últimas, casi que un panfleto. Tampoco es casual que Benda se haya opuesto a cualquier tipo de particularismo en una postura antinacionalista y anticonservadora. Rincón sería, al final, un lúcido diletante. Lo clave aquí es el estilo de Rincón, el moverse entre lo macroscópico y lo microscópico, el juntar los rasgos de una época con los pormenores, la analítica transversal con la anécdota, el archivo y el concepto. La cuestión es que, más que a Benda, Rincón quizás se acerca al tono de un historiador como Carlo Ginzburg en Mitos, emblemas e indicios y en El hilo y las huellas. En todo caso, si estamos frente a una "novela" al leer los textos de Rincón —y ¿por qué no?-, sería cuando menos una novela psicoanalítica: multicausal, polivalente, traidora. "Nuestra imperiosa necesidad de hallar nexos causales”, escribe Freud (2010),

[...] se conforma con que cada proceso tenga una causa demostrable; pero en la realidad exterior difícilmente sucede tal cosa, pues cada fenómeno parece estar más bien sobredeterminado, presentándose como efecto de múltiples causas convergentes. Intimidado ante la insuperable complejidad del suceder, nuestro conocimiento opta por un nexo determinado, en contra de otro; establece contradicciones inexistentes, sólo debidas a la arbitraria destrucción de relaciones más amplias (p. I3I).

Parte de esas relaciones más amplias consiste no solo en situar a Colombia en un plano global, transnacional, sino en algo que va más allá de contar el pasado: las relaciones entre literatura e historia apuntan tanto a contar, narrar o escribir la historia (el pasado, digamos) como a "elucidar las operaciones temporales (causalidad, cruzamiento, inversión, condensación, etcétera)” (De Certeau, 2007, p. 46), pues, como dice Michel de Certeau, "la literatura es el discurso teórico de los procesos históricos” (p. 41). Es decir que si estamos frente a una novela de corte psicoanalítico, la pregunta entonces ya es otra: ¿es una buena o una mala novela?, ¿evalúa de manera sugerente los síntomas del cuerpo social que disecciona? Si esto es así, esta- 
mos ante la posibilidad de que las "novelas psicoanalíticas" de Rincón se alejen de las tendencias hostiles a la vida que Nietzsche halla en los modos de vida y de escritura convencionales, oponiéndolas así a la escritura del hombre moral, quien "con sus normas absolutas" emprende el recuento del pasado desde los saberes disciplinados -la historia-. Con Rincón la pregunta se desplaza del qué ha pasado hacia el qué nos ha pasado. Y, ¿qué no deja de pasar en nosotros?

En su conferencia "El Nacimiento de la tragedia" en el evento "Nietzsche Vivo", finalizando el siglo xx, Ramón Pérez Mantilla (2018), colega de Rincón, recordaba que en dicho libro Nietzsche está haciendo una contraposición valorativa muy importante, “nada menos que entre moral y arte, determinándola en la medida en que el arte estaría del lado de la apariencia, del engaño, de la óptica, del perspectivismo e incluso del error, mientras que la moral parecería estar muy cercana a la veracidad de Dios” (p. 276). La cuestión es si estamos o no dispuestos a salir del análisis moral de la política, de la literatura, de la estética. Y por ahí va Rincón, al tomar el camino de trazar las fuerzas no visibles. Es entonces la suya tanto una estética de las perspectivas — ¿quién habla?, ¿quién es el que quiere eso?-, como una estética en perspectiva, errática, centáurica y no ciclópea, dotada de mil ojos en vez de uno solo. Capaz no solo de ponerse a tono con la dispersión, sino de ser dispersión, de ser meandro. Mil ojos, mil lenguajes y textos interferidos, reciclados y reutilizados por Rincón en los textos que compuso. E1 pensamiento, como bien lo vio Peirce (2012), más que a encadenamientos y eslabones, responde a cables: el mundo y el pensamiento no están encadenados, en cadenas y eslabones: están cableados, por "un cable cuyas fibras pueden ser muy delgadas, siempre y cuando sean suficientemente numerosas y estén íntimamente conectadas" (p. 73). El estilo de Rincón es, lo anotamos en otro momento, pragmatista; elabora una crítica pragmática de la “voluntad de verdad”(Sánchez Lopera, 2012).

Por eso frente a la sugerencia de hacer de Rincón un diletante, puede preguntarse si aquello que parece fragmentación temática — como se sabe, Rincón abordó el barroco, la memoria, el boom, las literaturas mundiales, el posmodernismo, etc.—, ¿no sería más bien su intento de medirse con lo que se llama “teoría”? Y, de otra parte, ¿no es esto síntoma, en parte, de un cierto tipo de intelectual que tiende a desaparecer? No se trata de una cuestión de brillantez intelectual, aunque la haya —así eso irrite a algunos de sus críticos y al sentido común de nuestra época-. Lucidez que, sin em- 
bargo, fascinaba, desconcertaba, y situaba en dilemas a algunos de sus estudiantes. ${ }^{11}$ Más bien se trata de una forma de relacionarse con el saber que al mismo tiempo usa y difiere de nuestros soportes actuales de memoria, escritura y oralidad. Los usa, pues los textos de Rincón nunca dejaron de ser palimpsestos e hipervínculos, operaciones de montaje y desmontaje, donde escribir es siempre reescribir, combinar: al analizar a Borges, Rincón recurre a la palabra inglesa coat, que "es tanto colcha de retazos de tela como cento o centón, obra hecha con frases completas o versos de otras obras, vueltos a combinar" (Rincón, 2004, p.15). Su propia escritura también rozará esas operaciones combinatorias, contaminando a la crítica con las artes del tejido y la literatura, envuelta ahora en un manto (o patchwork) que a cada movimiento cambia de pliegue.

La suya es, en suma, una temporalidad no simultánea de la escritura - “transmedial", como de hecho llama a la literatura de Borges: una escritura, a su vez, de aquello que es simultáneo, pero que no es copia; diverge, es desemejante... simulacroEso también explicaría la renuencia a acoger la obra de Rincón no solo en Colombia; también en Alemania y Estados Unidos. Por eso es que en parte Rincón genera tanta resistencia frente a su escritura, en tanto un crítico como Ángel Rama sigue generando tanta aceptación a lo largo y ancho de las Américas: pues Rincón se intenta instalar en el mundo de los simulacros, que es el nuestro. Y que fue el de Borges, y su literatura, por lo cual "la posibilidad de la repetición construida sobre la (di)similitud es su corolario" (Rincón, 2004, p. 15). Por eso, a su vez, Rama dijo lo que dijo sobre Borges, según nos cuenta Rincón en el marco de la discusión de las imposibilidades del "qué hacer con Borges" en la década del 50 del siglo xx. "No tiene entonces por qué sorprender", escribe Rincón, "la manera tan enfática como Ángel Rama situaba en 1959 a Borges, desde la Revista Nacional de Montevideo, dentro de su particular visión de la historia de la literatura y los vínculos que imaginaba con el devenir histórico”:

“Él [Borges] ha socavado la tradición realista de las letras españolas, pero su tarea ha sido de simple destrucción y nada ha hecho para imponer paralelamente la creencia en un trasmundo fantástico que legitime sus historias fantásticas. Ha jugado con él, pero a pesar de ser un creador de cuentos fantásticos ha dejado indemne el mundo realista que sostiene la literatura realista" (Rama). Es notable que ni por un momento hayan pensado en considerar a Borges en relación con Joseph Conrad, Edward M. Foster, James Joyce o Thomas Stearn Eliot, con los acentos sinceros y honestamente asqueados ante su sociedad y las instituciones que la definían (Rincón, 2004, p. 50).

11 Un breve testimonio de uno de sus alumnos puede leerse en: https://elcacha.co/2018/carlos-rincon-criticocultural/ También puede verse el relato, no exento de dilemas y problemáticas, que narra el propio Rincón sobre su experiencia con un grupo de estudiantes colombianos, en el posfacio al libro Fealdad, gracia y libertinaje. Estética y modernidad en el pensamiento colombiano [1940-1960]. 
Recordemos que la filosofía de la diferencia, seducida también por Borges, ha ejecutado un notable juego de ópticas con la noción de simulacro en tanto disimilitud, ensamblaje y reunión simultánea, y disimulo —el movimiento desde el esto es lo otro a esto deviene lo otro, esto se repite en tanto otro-: "simular es, originalmente, venir juntos", dice Foucault (1999, p. 205). Mundo de simulacros entonces, fantasmático, sin sustancias ni autenticidades. Por lo demás, no hay que olvidar que la fragmentación es un problema para un pensamiento que se construya desde la unidad; es decir que sí es posible que los fragmentos, los rastros, se relacionen — solo que lo hacen en términos que no son los de la unidad-. Cabe además preguntar: ¿y si en lugar de dispersión o fragmentación, lo que hay en su obra es una manera de componer mundos y literaturas dispares, mundos simulados y virtuales? Es, de nuevo, la gota y la ola y el mar de Leibniz. Sobre Rincón se puede decir lo que él mismo dijo sobre Gerardo Reichel-Dolmatoff, otro polémico autor: "Su trayecto logró ser, en ese sentido, modelo de translatio entre culturas y entre mundos, traslado de significaciones de una orilla a otra” (Rincón, 2015, p. 275).

Esto, claro, no implica que deje de haber truncamientos. A pesar de que Rincón vuelca la obra de Reichel-Dolmatoff sobre el flujo de la etnología y la arqueología globales, siguen abiertos los interrogantes sobre el pasado nazi de esta figura central de la antropología colombiana. Dada la sutileza con que maneja las artes de la ironía, sorprende cómo Rincón casi que pasa por alto esta situación, confinándola a una nota explicativa al pie de página, sin convertirla en un problema a pensar. ${ }^{12}$ Está, asimismo, la nota un tanto exaltada sobre la publicación de la obra de Hernando Téllez por parte del Instituto Caro y Cuervo, institución a la que tantas veces criticó ácidamente (Rincón, 2018a, pp. 15-18). En momentos así, Rincón parece sucumbir a la tentación de volver a presentar lo que ya estaba ahí, repetir lo dado, o lo que debió haber estado allí: clamar por más re-presentación.

Más allá de esos lapsus, el trabajo de Rincón se sitúa a contrapelo de tantos sociólogos, politólogos e historiadores que, desencantados, han dado el viraje de

12 El rol de Gerardo Reichel-Dlmatoff, como figura central de la antropología colombiana, es polémico debido a su pasado nazi (explícito durante 1934-1936). El mismo Rincón da cuenta de ello en una nota al pie de página (2015, pp. 263-264). Puede verse el dosier de la Revista Antipoda n. ${ }^{\circ} 27$ de 2017 — con textos de Claudio Lomnitz, Erna von der Walde, Gerhard Drekonja-Kornat y Roberto Suárez M.- para una revisión a fondo de la polémica, desatada por la intervención de Augusto Oyuela en el LIV Congreso Americanista, Vienna, Austria, en julio 17 de 2012. No obstante, la intervención de Oyuela, bastante moralista, se acerca más al sermón en torno al "padre" muerto de la arqueología. 
la desilusión y ahora condenan las resistencias y las insurgencias como vandálicas —este presente, dicen, no es momento para revueltas-. En efecto, los dos últimos libros de Rincón hacen una crítica de la dominación tecnocultural del intelectual público predominante en Colombia: del anticomunista posmoderno, miembro de una tecno-academia que, en parte, saltó de las aulas a las oficinas públicas con la reciente reelección del proyecto reaccionario en Colombia. Intelectuales que, más que un caso excepcional o local, conforman un tipo social que responde a la pregunta nietzscheana por el "quién”, “¿quién valora?”, “¿quién, qué tipo de humano?”13 — tipología para la cual Rincón dejó señas diversas-. Solo que el quién es aquí un tipo de humano presa de un particular afecto, el desprecio. Podría decirse que estos intelectuales tienen un problema con el tiempo: bien sea con el pasado o con el presente, asemejándose al sujeto reactivo descrito por Alain Badiou. Por eso quieren disciplinarlo y someter las formas de narrarlo.

El ejemplo más perverso es el del actual director del Centro Nacional de Memoria Histórica ( $\mathrm{CNMH}$ ) en Colombia, quien después de escribir lo que escribió sobre "la mentalidad de las élites sobre la violencia en Colombia", hoy no solo se pliega a ellas en el presente, sino que es uno de sus escribas en la reescritura negacionista de lo que ha pasado. ${ }^{14}$ También está lo sucedido con el director actual del Archivo Nacional, Enrique Serrano, quien de paso defiende una culposa hipótesis (reactiva) sobre la Conquista y el "ser” nacional, al preguntar “¿por qué fracasa Colombia?”; ${ }^{15}$ y con el actual fiscal general, el abogado y amigo desde sus tiempos de estudiante del actual presidente, Francisco Barbosa, quien en cuestión de meses pasó de defender de forma acérrima el acuerdo de paz con la insurgencia FARC-EP, a atacarlo con la virulencia tipológica del hombre del resentimiento. O el (ya hoy ex) director del "Museo de la Memoria", que con el emblema de que "no se debería censurar ninguna posición”, de "libertad de opinión”, por lo cual “deberían tener espacio todos”, convierte la memoria de lo común en memoria estatal, habilitando el todo vale. ${ }^{16}$ Todo un movimiento restaurador, neoconservador, que

\footnotetext{
13 Esto es lo que Gilles Deleuze (2002) llama “La pregunta nietzscheana, ‘¿quién?”' (pp. 73, 110, 177).

14 https://www.elespectador.com/noticias/politica/el-basta-ya-no-representa-el-amplio-espectro-deinvestigadores-dario-acevedo-articulo-879878

15 Puede verse una crítica de la postura reactiva de Serrano, a la luz de la historia crítica, en Schuster (2016).

16 https://www.elespectador.com/colombia2020/el-museo-de-la-memoria-seguira-siendo-de-las-victimasrafael-tamayo-articulo-876750
} 
convierte a la ya mencionada isegoría — igualdad en el derecho a la palabra - en una suerte de metaderecho donde cada cual tiene "su verdad", esto es, en el "cada cual verá" del anything goes nihilista - lo cual termina, además, suprimiendo la parresia, el decir verdad-.

Y aquí es donde toma toda su fuerza la mentira - la mentira en tanto falso pluralismo-. Mas no se trata aquí de la mentira en sentido religioso; de la mentira en sentido moralista. De ser "honesto" —en el sentido cívico o ético- Dice Nietzsche (2008): "Nadie ha llegado a comprender el problema de la veracidad. Lo que se dice contra las mentiras son ingenuidades de maestro de escuela, y sobre todo el mandamiento de ¡'no mentirás'” (p. 6 [332]). En efecto, Rincón se toma el paciente y terrible trabajo de contrastar la experiencia colombiana con la experiencia global. No solo la enuncia, como hacen las élites políticas, económicas y culturales con sus simulaciones y auto monumentalizaciones. Al final lo que muestra Rincón es el poder de la mentira sostenida a nivel de todo el cuerpo social: no las potencias de lo falso, es decir, lo falso en tanto valor extra-moral, sino el poder de una mentira que crece perversamente al interior de la moral (intra-moral). Retrata, pues, las consecuencias vividas en Colombia por una generalizada "voluntad de no conocer", una voluntad desconectada de la experiencia.

Porque con Rincón no se trata de una "denuncia”, de mostrar un secreto oculto. El presunto "secreto" ya está confesado por doquier, en las calles, en las redes sociales, y hasta en los medios masivos de comunicación. La cuestión es hacer visible lo que no está oculto — pero es invisible—. Así eso invisible sea atroz. Pues solo estando a la altura de lo vergonzoso que hemos podido llegar a ser es que se atisba la novedad — el acontecimiento, con toda su peligrosidad-. Es decir que se trata de describir nuestros horrores. Pero hacerlo sin resentimiento. Como lo intentó hacer Rincón. Y es a eso a lo que su partida nos invita.

\section{Referencias bibliográficas}

Benjamin, W. (2003). La obra de arte en la época de su reproductibilidad técnica (urtext). México D.F.:

Editorial Itaca.

De Certeau, M. (2007). La “novela” Psicoanalítica. Historia y Literatura. En Historia y Psicoanálisis.

Entre Ciencia y Ficción (pp. 1-22). México D.F.: Universidad Iberoamericana.

Deleuze, G. (2002). Nietzsche y la filosofía. Barcelona: Anagrama. 
Deleuze, G. (2006). Exasperación de la fllosofía. El Leibniz de Deleuze. Buenos Aires: Cactus.

Foucault, M. (1999).La prosa de Acteón. En Entre filosofía y literatura. Obras Esenciales (Vol. 1, pp. 201-213). Barcelona: Paidós.

Freud, S. (2010). Moisés y La Religión Monoteista. En Moisés y la religión monoteista (pp. 64-113). Madrid: Alianza Editorial.

Hernández, E. (2019). Nietzsche. Comunicación personal. 6 Oct.

Karl, Robert. (2018). La paz olvidada. Politicos, letrados, campesinos y el surgimiento de las FARC en la formación de la Colombia contemporánea. Bogotá: Librería Lerner.

Nancy, J. L. (2002). La imagen-lo distinto. Revista Laguna 11, pp. 9-22.

Nietzsche, F. (2008). Fragmentos Póstumos II (1875-1882). Madrid: Tecnos.

Peirce, C. S. (2012). Algunas consecuencias de cuatro incapacidades. En Obra Filosófica Reunida. Tomo I (1867-1893) (pp. 72-99). México D. F.: Fondo de Cultura Económica.

Pérez Mantilla, R. (2018). El Nacimiento de la Tragedia. En P. Montero, D. Figueroa y A. Bernal (Eds.). Fealdad, gracia y libertinaje. Estética y modernidad en el pensamiento colombiano [1940-1960] (pp. 275-288). Bogotá: Universidad Nacional de Colombia.

Rincón, C. (2000). Comunicación trasatlántica. Entrevista a Carlos Rincón. En E. Spielmann, F. Nelle y N. Bandenberg (Eds.). Exzentrische Räume. Festschrift für Carlos Rincón. Stuttgart: H.D. Heinz.

Rincón, C. (2004). Mapa, distopía, simulacro: El Inmortal, de Jorge Luis Borges. En C. Rincón y J. Serna Arango (Eds.). Borges, lo sugerido y lo no dicho. Bogotá: Siglo del Hombre Editores.

Rincón, C. (2014a). 1885: La Atenas suramericana en la capital de la modernité. En Íconos y mitos culturales en la invención de la nación en Colombia (pp. 197-240). Bogotá: Universidad Javeriana.

Rincón, C. (2014b). El ícono negativo por excelencia. Celebración y escarnio del Conde de Cartagena, General Pablo Morillo. En Íconos y mitos culturales en la invención de la nación en Colombia (pp. 117-135). Bogotá: Universidad Javeriana.

Rincón, C. (2014c). En lugar de un epílogo: una fotografía para recordar. En Íconos y mitos culturales en la invención de la nación en Colombia (pp. 321-338). Bogotá: Universidad Javeriana.

Rincón, C. (2015). Consideraciones morales sobre el oro sagrado de los indios y el Museo del Oro del Banco de La República. En Avatares de la memoria cultural en Colombia. Formas simbólicas del Estado, museos y canon literario (pp. 233-286). Bogotá: Universidad Javeriana.

Rincón, C. (2018a). Homenaje a Hernando Téllez 1908-1966. Tres Fichas. Revista Iberoamericana LXXXIV (262), pp. 15-18. 
Rincón, C. (2018b). Posfacio. Informe para una academia: sobre un proyecto de libro acerca de estética moderna en Colombia. En P. Montero, D. Figueroa y A. Bernal (Eds.). Fealdad, gracia y libertinaje. Estética y modernidad en el pensamiento colombiano [1940-1960] (pp. 345-364). Bogotá: Universidad Nacional de Colombia.

Rodríguez, M. (2019). Redimir a Nietzsche (por enésima vez). Logos. Anales Del Seminario de Metafísica 52, pp. 161-69.

Sánchez Lopera, A (2012). Carlos Rincón y la crítica de voluntad de verdad. Una pragmática de la crítica literaria. Estudios de Literatura Colombiana 30, pp. 81-107.

Scavino, D. (1999) Diferencias y repeticiones. Clarín. Suplemento de cultura. 4 de abril.

Schuster, S. (2016). Reseña del libro ¿̇Por qué fracasa Colombia? Delirios de un país que se desconoce a sí mismo. Desafios 28 (2), pp. 427-433.

Silva, R. (2017). Sobre el fracaso de una nación. Avatares de la memoria cultural en Colombia. Formas simbólicas del Estado, museos y canon literario. Carlos Rincón. Boletín Cultural y Bibliográfico 51 (93), pp. 139-140. 